\title{
Marea negra
}

\author{
Lourdes Freixa i Solé \\ IESM Ferran Tallada
}

Es tracta de simular l'efecte de la marea negra provocada per l'abocament de petroli al mar, estudiar les seves conseqüències i sensibilitzar l'alumnat envers la problemàtica de la contaminació.

\section{MATERIAL}

Vas de precipitats, cristal-litzador, ous durs, oli, detergent, paper mil.limetrat

\section{DESENVOLUPAMENT}

1) Per veure què passa amb els ous dels ocells que es troben en una marea negra, col-loqueu oli en un vas de precipitats i poseu-hi tres ous durs. Traieu el primer ou al cap de 10 minuts, el segon al cap de 20 minuts i el tercer al cap de 40 minuts. Traieu la closca, examineu-los i compareu-los amb un ou dur control que no ha estat submergit en oli. Quin efecte pot tenir l'oli (o el petroli) en els ous dels ocells?

2) Agafeu un vas de precipitats parcialment omplert d'aigua, afegiu una cullerada d'oli i observeu la interacció entre l'oli i l'aigua. Imagineuvos que l'aigua del bol és el mar i que la taca d'oli és el petroli que ha vessat d'un petrolier. Per simular la marea negra, com que les aigües del mar sempre estan en moviment, haureu de moure l'aigua amb la cullera. Observeu què passa amb l'oli i l'aigua. Per veure com es netegen les marees negres heu de col-locar una gota de detergent en el bol i tornar a remenar fent ones amb més o menys intensitat. Observeu i compareu els resultats.

3) Per calcular la superfície afectada en un abocament de petroli, agafeu un cristal-litzador (o un recipient poc profund), ompliu-lo parcialment amb aigua i afegiu-hi $10 \mathrm{ml}$ d'oli. Després mesureu l'àrea recoberta per l'oli amb un tros de paper mil-limetrat. Utilitzant aquesta informació, calculeu l'àrea que podrà ser afectada per un abocament de petroli d'un petrolier que transporta 1.000.000 de litres.

4) Comenteu què fer amb els diferents tipus d'oli (de cuina, de motor de moto o cotxe, etc.) per tal d'evitar abocar-los al clavegueram.

\section{OBSERVACIONS}

Aquesta experiència és una adaptació d'una de les activitats de "Hàbitat. Guia d'activitats per a l'educació ambiental" publicada per l'Institut d'Educació de l'Ajuntament de Barcelona.

La pràctica es fa amb oli donada la dificultat per a aconseguir petroli. A més, en ser un material quotidià, augmenta l'interès dels alumnes vers la problemàtica ambiental en veure que tots podem contribuir a la contaminació del mar.

Aquesta experiència té una durada d'una hora i el material necessari és molt senzill; fins i tot es pot realitzar a l'aula o a casa substituint el vas de precipitats per un bol poc profund.

Per no preparar molts ous durs, es pot dividir la classe en quatre grups i que cada grup es responsabilitzi de controlar un dels ous. Es poden posar junts en un sol vas de precipitats gran i així no es necessita tanta quantitat d'oli.

Aquesta pràctica consta de diverses experiències que es realitzen simultàniament i aprofitant el temps d'espera de la primera.

Cal tenir cura amb el material i evitar esquerdes en els ous durs al llarg de l'experiència per no alterar els resultats. Es pot apreciar una pèrdua del volum de la cambra d'aire dels ous submergits en oli i que aquesta augmenta amb el temps d'exposició.

Es pot aprofitar la tercera experiència per treballar les potències de 10 i veure que no sempre és necessari l'ús de la calculadora quan tenim valors elevats. A més, permet treballar el càlcul d'àrees de superfícies irregulars.

El darrer punt, el destí que donem als diferents tipus d'oli, és molt breu però molt important donat que aporta les solucions per evitar la contaminació per part dels ciutadans. 